\title{
Exposure to Reversine affects the chondrocyte morphology and phenotype in vitro
}

Gasparini S. ${ }^{1 \#}$, Villa F. ${ }^{1 \#}$, Molfetta L. ${ }^{2}$, Repaci E. ${ }^{1}$, Castagnola P. ${ }^{3}$, Quarto R. ${ }^{1}$, and Giannoni P. ${ }^{1}$

1: Stem Cell Laboratory, Dept. Experimental Medicine (Di.Me.S.), University of Genova,

Advanced Biotechnology Centre, L.go R. Benzi, 10; 16132 - Genova, Italy; 2: Orthopedic Unit; Dept. of Neuroscience, Rehabilitation, Ophthalmology, Genetics and Maternal-Infant

Sciences (Di.N.O.G.M.I), University of Genova, L.go P. Daneo 3, 16132 - Genova, Italy; 3:

IRCCS AOU San Martino-IST, L.go R. Benzi, 10; 16132 - Genova, Italy

Short title: Reversine affects chondrocyte morphology and phenotype

\section{Corresponding Author:}

Dr Paolo Giannoni

Stem Cell Laboratory

Dept. Experimental Medicine, University of Genova

c/o Advanced Biotechnology Centre

L.go R. Benzi, 10; 16132 - Genova, Italy

Tel: +390105558436

Fax: +390105558501

e-mail: paolo.giannoni@unige.it

\# These authors equally contributed to the presented work.

This article has been accepted for publication and undergone full peer review but has not been through the copyediting, typesetting, pagination and proofreading process which may lead to differences between this version and the Version of Record. Please cite this article as doi: $10.1002 /$ term. 2515 


\section{Abstract}

Articular chondrocytes derived from osteoarthritic tissues (OA-HAC) show a severely reduced chondrogenic commitment. This impairment undermines their use for tissueengineered cartilage repair, which relies on cell proliferation and growth to meet the therapeutic needs but also on efficient cell plasticity to recover the chondrogenic phenotype. Reversine (Rev), a 2,6-disubstituted purine inhibitor of spindle-assembly checkpoints, was described to convert differentiated mesenchymal cells to their undifferentiated precursors. We hypothesized that Rev exposure could divert OA-HAC to more plastic cells, re-boosting their subsequent commitment. HAC were enzymatically released from osteoarthritic cartilage specimens, expanded for two weeks and treated with $5 \mu \mathrm{M}$ Rev in DMSO or with DMSO alone for 6 days. Cell growth was assessed by the AlamarBlue $^{\mathrm{TM}}$ assay. Cytoskeletal structure, endoproliferation and caspase-3immunopositivity were assayed by epifluorescence microscopy. The OA-HAC chondrogenic performance was evaluated by quantitative RT-PCR for GAPDH, Sox9, Aggrecan (Agg), type-II collagen (Col2), Ki67, CyclinD1, TGF $\beta-1,-2$ and -3 , Interleukin 1- $\beta$ and -6 (IL-1 $\beta$, IL-6); SMAD 3 and 7, and VEGF. Rev-treated OA-HAC recovered polygonal morphology and reduced Ki67 expression and proliferation. Cell-cycle impairment accounted for altered cytoskeletal organization, endoproliferation and apoptosis, while a compensatory mechanism sustained the increased CyclinD1 transcript levels. Sox9, Agg and TGFs were overexpressed, but not Col2. Interleukins transcripts were massively down-regulated. These events were doserelated and transient. Overall, in spite of a higher Rev-induced transcriptional activity for ECM components and in spite of a Rev-treated cell phenotype closer to that of the 3Dnative articular chondrocyte, Reversine effects seem unleashed from a full regained chondrogenic potential.

Keywords: Chondrocyte, Differentiation, Reversine, Articular cartilage, In vitro

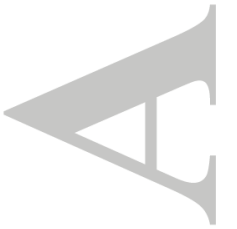




\section{INTRODUCTION}

Cell-based therapies have been suggested for clinical treatments of joint cartilage in degenerative diseases. However, in the context of osteoarthritis (OA), cartilage tissue engineering has not held the premises and it has not yet become a breakthrough in therapy. Indeed differentiated chondrocytes show stem cell markers, indicating the transitamplifying nature of these cells (Tiku and Sabaawy, 2015). It has also been reported that more progenitors resided in the OA synovial fluid (Jones et al., 2008) and that OA cartilage contains more $\mathrm{CD}_{105^{+}}$and $\mathrm{CD} 166^{+}$cells than healthy tissue, possibly as a direct response to cartilage damage or by migration from the synovia and/or subchondral bone marrow (Alsalameh et al., 2004). In spite of the availability of potential repair cells, however, tissue regrowth is generally not observed within OA pathological environments, particularly if vertical fissures require lateral integration of the neo-generated tissue (Brandt et al., 2008). Progenitor cells extracted from patients with joint degenerative cartilage defects have in fact always exhibited a markedly lower chondrogenic potential in vitro, either if derived from the synovia (Krawetz et al., 2012), from the bone marrow (Murphy et al., 2002) or from the cartilage itself (Dorotka et al., 2005). In addition, the alterations in the levels of cytokines, chemokines and growth factors, due to the disrupted tissue homeostasis, are clear sources of concern (Jayasuriya et al., 2014). In spite of the attempts performed to exploit cell therapy for regenerative purposes, to refine the re-implantation techniques, to up-grade specific culture conditions and to use advanced biomaterials to meet the request of orthopedic surgeons (Mardones et al., 2015), the bottom line of a large body of past and current literature is that OA chondrocytes are not at all suitable chondroprogenitors to be re-addressed toward proliferation and differentiation to replace the lost tissue. A strengthening of their differentiation and re-differentiation potential is therefore crucial, if 
those cells are envisaged for cartilage repair, being OA patients the largest clinical target for cartilage resurfacing. In this light, we took into consideration the early work of Chen and coll., which screened combinatorial libraries of small molecules to identify target compounds that can induce the de-differentiative process (Chen et al., 2006). The potential of reversine was confirmed in myoblasts dedifferentiation (Chen et al., 2007) or in dermal fibroblasts (Chen et al., 2004); its action was exploited to induce cell differentiation toward the neuroectodermal lineage (Lee et al., 2009) while its growth inhibition effect was confirmed in cancer cell lines (Bijian et al., 2013). Although somatic cells are thought to be stably committed to their terminal fate, emerging evidences have indicated that dedifferentiation may occur upon nuclear transfer (Wilmut et al., 1997), cell fusion (Ying et al., 2002) or genetic reprogramming (Karagiannis and Yamanaka, 2014). Reversine, instead, a 2,6 di-substitued purine, seems to chemically reprogram cells to a different plasticity level, an ability that provides an attractive clinical appeal. The mechanism of action is thought to interfere with the activity of Aurora kinase B (Amabile et al., 2009). The members of the Aurora S/T kinase family are involved in the stabilization of the microtubule attachment at the kinetochore location of each chromosome, since their phosphorylating activity on target proteins decrease microtubule-binding affinity at the centromers (Santaguida et al., 2010). These proteins, then, contribute to the great deal of accuracy of the mitotic process. Thus the use of small molecules that increase mammalian cell plasticity could provide benefits to generate different types of progenitors for therapeutic applications, as already tested to maximize cardiomyocyte development from progenitor cells (Pikir et al., 2012). Moreover reversine was also shown to support the expression of a de-differentiated phenotype in cells of the annulus fibrosus, potentiating the chondrogenic differentiation of the treated cells, although derived from normal tissue (Saraiya et al., 2010). Based on these findings we 
evaluated if reversine treatment could be applied to ex-vivo cultured human OA articular chondrocytes to reprogram these lineage-committed cells and to obtain more performing chondrocytes. This would, in turn, amplify the therapeutic indications of cell-based cartilage resurfacing, particularly reducing the initial limitations relative to donor tissue health conditions.

\section{MATERIALS AND METHODS}

\subsection{Cell cultures}

Human articular chondrocytes (HAC) were isolated from biopsies derived from three different male donors (age range: $68-83$ years) undergoing total knee arthroplasty. Patients had signed an informed consent approved by the Ethical Committee of the IRCCS-AOU San Martino-IST, Genova, Italy, prior to surgery. Cartilage specimens were derived from relatively normal and from frankly osteoarthritic areas of the articular cartilage of the femoral condyles of each donor. Part of tissue samples were processed for grading (ICRS scale) and immunocytochemistry, as subsequently detailed. The remaining cartilage specimens of each area were cleared of connective tissue and/or subchondral bone, minced in small fragments and rinsed in fresh phosphate-buffered saline (PBS, $\mathrm{pH} 7.2$ ). Cartilage fragments were enzymatically digested as previously reported (Narcisi et al., 2012). The isolated primary HAC were henceforward cultured in complete medium (Coon's modified Ham's F12 medium (Biochrom A.G., Berlin, Germany) with 10\% fetal calf serum (FCS), 1\% Lglutamine) which was changed 3 days after plating and then twice a week. The culture dishes used for cell plating were pre-coated for 24 hours with culture medium to ease cell adhesion to the plastic. HAC from each donor were expanded in vitro until passage 1 , detached by trypsinization, collected, counted and replated either for growth assessment, 
immunofluorescence or gene expression assays in the presence/absence of different concentrations of Reversine (diluted in dimethyl sulfoxide, DMSO; final concentrations of $500 \mathrm{nM}, 1 \mu \mathrm{M}$ or $5 \mu \mathrm{M})$. Control HAC were exposed to solvent DMSO alone. Aliquots of primary HAC of each donor/area were also used to generate high cell-density micromass cultures and maintained in chondrogenic medium for the following two weeks (Johnstone et al., 1998).

\subsection{Proliferation assays}

For growth kinetic experiments, $3 \times 10^{4} \mathrm{HAC}$ were seeded in 24-well plates and maintained in F12 medium for additional $24 \mathrm{~h}$. Non-attached cells were removed and cell growth evaluated by the Alamar Blue ${ }^{\mathrm{TM}}$ assay (Invitrogen, Milano, Italy) as indicated by the manufacturer. Briefly, at fixed time-points $(0,1,2,3$ and 6 days after plating) cells, in all culturing conditions, were exposed to a complete medium containing $10 \%$ of the vital dye for 4 hours. Collected supernatants were spectrophotometrically evaluated at 600 and 570 $\mathrm{nm}$ : absorbance variations correlate with the number of cells. Each time point, for each primary culture and condition, was assessed in triplicate/quadruplicate. Cell doublings were calculated with respect to the number of initially plated cells.

\subsection{Image analysis}

Images of cells in all different experimental culture conditions were acquired using a Nikon Digital Sight DS-5Mc camera, mounted on an OlympusBX5 1 fluorescence microscope, using Nikon imaging software NIS-Elements F, release 2.20. Image analysis was performed using the National Institute of Health Image J freeware (release 1.38X; http://rsb.info.nih.gov/iJ/). 
Criteria used to include cells in the morphological evaluation were: (a) identification of single cells and of all their boundaries; (b) contemporaneous identification of the nuclear boundaries within the same cells; (c) identification of a major and a minor axis within the cell shape $\left(C_{y}\right.$ and $C_{x}$, respectively); (d) identification of a major and a minor axis within the nucleus shape ( $N_{y}$ and $N_{x}$, respectively). Axes were then measured by the program functions and the morphological ratio $\left(C_{y} / C_{x}\right) /\left(N_{y} / N_{x}\right)$ calculated. A minimum of 100 cells/treatment/primary culture were assessed to quantify the changes of the cell shape as a function of the culturing conditions.

\subsection{Immunohistochemistry and Immunofluorescence assays}

Cartilage specimens were washed in PBS, pH 7.2, fixed overnight in $4 \%$ paraformaldehyde, rinsed in PBS and embedded in paraffin. Sections (5 $\mu \mathrm{m}$ thickness) of normal (N) or osteoarthritic areas (OA) were cut, de-waxed and stained with Toluidine Blue, Alcian Blue an Safranin-O to evidence section morphology, according to standard protocols(Narcisi et al., 2012), also applied for cytochemical analysis of cell pellets resulting from micromass cultures. Tissue and pellet sections were also challenged with anti type II collagen antibody (Developmental Studies Hybrydoma Bank, University of Iowa, lowa City, lowa, USA, cat.n. CIIC1), and revealed with standard procedures using a biotinylated goat-anti mouse secondary antibody (DakoCytomation, Dako Denmark A/S; DK-26000 Glostrup, Denmark; cat.n. E0433). Cultured HAC were instead fixed in $4 \%$ paraformaldehyde, rinsed in PBS and permeabilized with Hepes $20 \mathrm{mM}$, pH 7.4, Sucrose $300 \mathrm{mM}, \mathrm{NaCl} 50 \mathrm{mM}, \mathrm{MgCl}_{2} 3 \mathrm{mM}$, Triton X-100 0.5\% for 5 min at RT. Permeabilized HAC were than challenged with anti- $\beta$ actin, anti- $\beta$ tubulin or anti-active Caspase III (Sigma Aldrich, St. Louis, MO, USA, cat.n. A- 
2228, T-8660, and C-8487, respectively) antibodies, subsequently revealed with FITC(Jackson ImmunoReasearch Lab. Europe Ltd., Suffolk, UK cat.n. 115-095-146) or PEconjugated (Jackson ImmunoReasearch Lab. Inc., cat.n. 111-116-144; or DakoCytomation, Dako Denmark A/S; DK-26000 Glostrup, Denmark; cat.n. R0439) secondary antibodies.

\subsection{High resolution DNA flow cytometric analysis (hr DNA-FCM)}

The DNA content in cell nuclei was determined as reported by Otto (Otto, 1994). Briefly, nuclei suspensions were obtained by incubating cells in lysis buffer containing Tween 20. Nuclei were filtered (50 $\mu$ m nylon mesh), stained with DAPI and analyzed using a CyFlowML multiparameter flow cytometer (Sysmex Partek, Norderstedt, Germany). An UV mercury lamp (HBO-100 long life, 100W) was used to excite DAPI and the emitted light was collected by using the Gratz setting (488 blue solid laser shutdown; $435 \mathrm{~nm}$ long pass filter).

\subsection{Western blots}

Total proteins were extracted using the $M-P R^{\circledR}$ Protein extraction reagent (Thermo Scientific, Pierce Biotechnology, Rockford, IL, USA) and quantitated by the Pierce BCA assay kit (Thermo Scientific). Equal amounts of total protein lysates per sample were subjected to 4\%-12\% SDS-PAGE separation and transferred on PVDF membranes by standard Western blotting. Membranes were blocked for $2 \mathrm{~h}$ in TBS-T buffer $(20 \mathrm{mM}$ Tris/ $\mathrm{HCl} ; 0.5 \mathrm{M} \mathrm{NaCl} ; 0.1 \%$ Tween20) containing 5\% dry milk powder, washed three times in TBS-T and incubated overnight at $4^{\circ} \mathrm{C}$ with anti-SOX9, anti-SMAD 2/3, anti phospho-SMAD 2/3 (Santa Cruz Biotechnology Inc. Europe, Heidelberg, Germany, cat.n.SC-20095, SC-6032 and SC-11769, 
respectively) or anti- $\beta$-actin (Sigma-Aldrich) in $5 \%$ low fat milk in TBS-T buffer. Immunodetection was performed adding HPR-linked secondary antibodies for $2 \mathrm{~h}$ at room temperature, followed by visualization with $\mathrm{ECL}^{\mathrm{TM}}$ Prime Western Blottting Detection Reagent, on Amersham Hyperfilm ${ }^{\mathrm{TM}} \mathrm{ECL}$ chemiluminescence film (all from Amersham-GE Healthcare Ltd.; Little Chalfont, UK).

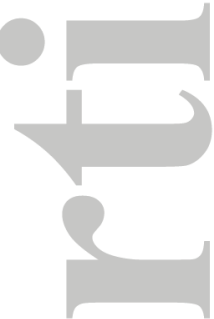

\subsection{Gene expression analysis}

Total messenger RNA was extracted according to the instructions of the PerfectPure RNA Cultured Cell Kit (5-Prime GmbH, Hamburg, Germany); cDNA pools were generated by using the SuperScript ${ }^{\mathrm{TM}}$ III First-strand synthesis system for RT-PCR Kit (Invitrogen). Primer sets for each gene were derived from published sequences (glyceraldehyde-3-phosphate dehydrogenase, GAPDH; Sox9; Aggrecan, AGG; type II Collagen; SMAD 3 and 7; Matrix Metalloproteinase 13, MMP-13; Vascular endothelial Growth Factor, VEGF; see(Narcisi et al., 2012)), or purposely designed (Cyclin D1; Ki67; Transforming Growth Factor $\beta-1,2$ or 3, TGF $\beta-1,2$ or 3); Interleukin 1- $\beta$, IL-1 $\beta$; Interleukin 6 , IL-6; see Table 1). Relative expression of each gene was assessed by sybr-green real time quantitative RT-PCR; cDNAs samples were amplified with the RealMasterMix SYBR ROX 2,5X (5'-Prime) in an Eppendorf Mastecycler Realplex ${ }^{2}$ apparatus, performing quadruplicate reactions for each sample as follows: $95^{\circ} \mathrm{C}$ for 3 minutes; 35 cycles at $94^{\circ} \mathrm{C}$ for $30 \mathrm{sec}, 60^{\circ} \mathrm{C}$ for $30 \mathrm{sec}, 72^{\circ} \mathrm{C}$ for $40 \mathrm{sec}$, and a final step at $72^{\circ} \mathrm{C}$ for $7 \mathrm{~min}$. The specificity of reaction products was counterchecked by melting curve analysis. Gene expression in each sample was normalized to the endogenous control gene 
GAPDH. Expression levels in DMSO control cells was set as reference for further normalization among different primary cultures.

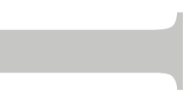

\subsection{Statistical evaluation}

To compare the effects on cell morphology of the various Reversine treatments across the different donors, a mixed effect linear statistical model was used, accounting for the repeated measurements within subjects (paired measurements) and for the different number of repetitions in each treatment group. Elsewhere the Mann-Whitney test was used. Whenever indicated ${ }^{*}: 0.05>p>0.01 ; * *: 0.01>p>0.001$ and ${ }^{* * *}: p<0.001$.

\section{RESULTS}

3.1 Reversine effects on cell growth and morphology.

All OA cartilage samples presented evidences of indentations, fissures, fibrillation and cell proliferation (Figure 1A). A reduced differentiation potential of OA-HAC was confirmed by the cells inability to generate matrix-rich micromass cultures: sections resulted negative to immunostaining against type II collagen (Figure 1B); at the same time their proteoglycan content did not evidence cytopositive reaction to Toluidine Blue or Alcian blue, as well as it did not allow detection of mature lacunae in the cultured pellets, with respect to the relatively normal (N) HAC counterparts (Figure 1B). OA-HAC were then expanded in the presence of different concentrations of Rev to assess its effects on cell growth and morphology. Growth kinetics were significantly impaired in Rev-treated cells within 6 days of exposure at the highest concentrations (1.0-5.0 $\mu \mathrm{M})$, whereas the lowest dose (500 nM) 
did not elicit any variation with respect to DMSO alone-treated controls (Figure 1C). Aliquots of cells, previously exposed to $5.0 \mu \mathrm{M}$ Rev for 6 days were shifted to the lowest Rev concentration (500 nM) for 6 additional days. Cell growth was resumed upon shifting, indicating that a constitutively high concentration of the drug was required to exert the observed effect on proliferation (Figure 1D). By converse Rev did not impair the proliferative activity of HAC derived from relatively normal areas of the same biopsies at any of the tested concentration (Figure 1E). Morphologically, an evident loss of the fibroblast-like appearance of the cultured cells was detectable in all experimental conditions in which Rev was used, independently of its concentration (Figure 2A and 2B). Prolonging the exposure time to $500 \mathrm{nM}$ Rev for additional 6 days did not elicit further variations; within the same time-frame, and in spite of a restored proliferative activity, OA-HAC shifted from $5.0 \mu \mathrm{M}$ to $500 \mathrm{nM}$ Rev did not regain a fibroblast-like morphology (Figure 2A). Indeed, after 6 days, immunostaining procedures for $\beta$-tubulin and $\beta$-actin clearly called for a massive rearrangement of the cytoskeletal structures of the Rev-treated cells (Figure 2C).

We then wondered if the morphological changes were contemporary to the effects exerted on cell proliferation. Hence, a time-dependent analysis of the appearance of the variations of the morphological determinants was performed, assessing the cell axes/nuclear axes ratio values at different timings upon Rev exposure. Shape changes appeared evident from the $4^{\text {th }}$ day of treatment, peaking at days $5-6$, concomitantly to the growth arrest effects (Figure 2D): within this timeframe in $5 \mu \mathrm{M}$ - Rev-treated OA-HAC, 69\% of the cells had gained a polygonal shape.

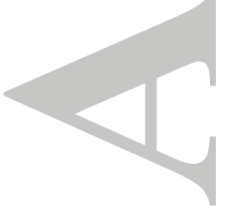


3.2 Reversine treatment affects cell proliferation by impairing cell cycle checkpoints.

The interference raised by Rev with the mitotic spindle organization is described to block cells mainly in the $G_{2} / M$ (Chen et al., 2007) and G1/S transitions (Piccoli et al., 2012). We confirmed this assumption also for osteoarthritic chondrocytes by quantitative RT-PCR experiments, assessing the Ki67 and cyclin D1 mRNA levels. Our results evidenced a drastic reduction ( $>50 \%$ ) of the transcript levels for Ki67, a well-known proliferation marker, in 1.0 or 5.0 $\mu \mathrm{M}$ Rev-treated OA-HAC. This effect accounted for the reduced proliferation and was accordingly undetectable in 500nM-treated cells (Figure 3A, left panel). The cell attempt to overcome the block of the G1/S transition was testified by a notably enhanced RNA messenger level for cyclin D1, which averaged a 10-fold increase for 1.0 and $5.0 \mu \mathrm{M}$ Revtreated OA-HAC (Figure 3A, right panel). We also performed an analysis of the cell cycle phase distribution based on DNA content assessed by hr DNA-FCM in control and Revtreated OA-HAC; results evidenced a remarkable increment in Rev-treated cells of the G2/M phase percentage (from $6.7 \%$ to $14.6 \%$ ), confirming the propensity of Rev to induce mitotic arrest and polyploidy. We therefore checked Rev-treated cultures for evidences of endoproliferation by nuclear counterstaining with DAPI; indeed, multiple nuclei could be detected within the same cells in all treated primaries (Figure $3 \mathrm{~B}$ and $3 \mathrm{C}$ ). Concomitantly to phenotypic changes, nuclear blebbing and active caspase-3-immunopositive cells were identified, suggesting that apoptotic onset was also induced upon Rev treatment (Figure 3D). The cultured fibroblast-like OA-HAC, once exposed to Rev, had therefore gained a new morphology, closer to that of the naïve cells in normal tissue.

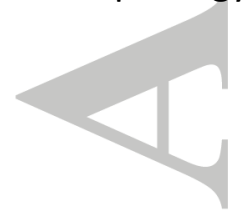




\subsection{Reversine-induced morphological changes coexist with a modified gene expression}

pattern in OA-HAC

We evaluated if the loss of fibroblast-like morphology in Rev-treated OA-HAC was also accompanied by a recovered expression of some relevant chondrogenic markers by means of real time RT-PCR analysis; we first focused onto the SOX9 transcription factor RNA messenger level, which peaked when OA-HAC were treated with the highest concentration of Rev, more than doubling the transcript level found in control cells (Figure 4A). Western blot and densitometric analysis confirmed the data for SOX9 also at the protein level, upon 6 days of exposure to Rev (Figure 4B and 4C). Enhanced mRNA transcript levels were additionally found for Aggrecan, displaying a 5- to 7-fold increase in treated cells with respect to untreated control OA-HAC (Figure 4D). In accordance to a reduced proliferative activity, Rev-exposed cultured chondrocytes did not overexpressed the type I collagen mRNA (data not shown), but they also did not show any significant up-regulation of the type II collagen transcript (Figure 4E), a specific marker of articular chondrocytes. On the contrary, the more responsive N-HAC not only averaged a $7.41 \pm 0.50$ fold-increase in Sox 9 expression in $5 \mu \mathrm{M}$ Rev-treated cells, but also showed a contemporaneous $5.17 \pm 0.70$ foldincrease in type II collagen expression (Figure $4 \mathrm{~F}$ and $4 \mathrm{G}$ ). We then assessed the mRNA levels of some members of the TGF gene family, which revealed up-regulation of TGF $\beta-1$ and $\beta$ - 2 transcripts upon 6 days of Rev exposure with respect to controls, reaching an 8 - and a 5-fold respectively (Figure 5). In Rev-treated N-HAC, instead, the expression levels of the TGF family members remained substantially unaltered (data not shown). Hence we evaluated the phosphorylation status of $\operatorname{SMAD2/3}$ in a western blotting setting, since receptor regulated SMAD 2 and 3 are canonically activated by TGF- $\beta$ extracellular signals. SMAD 3 mRNA levels are increased after Rev treatment at the highest concentrations, but 
no sign of increased phosphorylation could be detected by western blot approaches (Figure $6 A, 6 B$ and $6 C$ ). On the contrary, the mRNA levels of the inhibitory SMAD7 resulted enhanced as a consequence of Rev exposure, reaching a 3-fold increase with respect to control DMSO only-treated OA-HAC (Figure 6D). A consequence of an altered fate of Revexposed OA-HAC is also suggested by a marked overexpression of VEGF and MMP13 mRNAs (Figure 6D).

A large body of evidence has previously supported the concept that chondrocyte hypertrophy may be started by inflammatory cytokines but that persistence of altered levels of pro-inflammatory molecules is, instead, detrimental to the osteogenic differentiation of bone marrow stromal cells (Kong et al., 2013). Indeed OA-HAC display higher levels of IL-1 $\beta$ and IL-6 mRNA than their normal counterparts (data not shown). Interestingly, Rev treatment lowers these levels in a dose-dependent fashion (Figure 6E); this effect is predominant on the IL-1 $\beta$ transcript, both amplitude- and time-wise, since it reduces the cytokine mRNA in OA-HAC treated with $5.0 \mu \mathrm{M}$ Rev, within 3 and 6 days of treatment, to $1 / 5$ and then to $1 / 15$ of the level in DMSO-alone treated OA-HAC, respectively. The downregulation of the IL- 6 transcript follows the same pattern, although it appears to be less prominent.

\section{DISCUSSION}

In this study we investigated the effects of Reversine on OA-HAC proliferation and differentiation to assess the potential of this purine inhibitor to elicit the cells chondrogenic commitment, and possibly to help bypass the current limitation of cell-based therapies in cartilage repair relative to OA-affected tissues. We observed that reversine induced 
apoptosis in OA-HAC primary cultures and inhibited their proliferation in a dose-dependent manner, while it did not modify the growth of chondrocytes derived from relatively normal areas of the same biopsies. This inhibition required 3-6 days to appear and was dependent on the continuous presence of the chemical in the medium. A slow duplication rate of OAHAC (Giannoni et al., 2005) may account for the observed time-lag needed to disclose the Rev-driven proliferation delay in the heterogeneous primary cultures used. The observed proliferation recovery may instead depend upon a fast regain of the cycling onset in those cells that have not changed their morphology (about 30\% of the cells, even after a full week of exposure to $5 \mu \mathrm{M}$ Rev). In particular, the Rev-treated OA-HAC underwent a G2/M arrest and a displayed a reduction of Ki67 expression; both effects are in agreement with the reported perturbation of the chromosome-microtubule attachment caused by Rev (Musacchio and Salmon, 2007) through inhibition of both Aurora B kinase and MPS1, a protein operating downstream of Aurora B required to recruit error correction checkpoint proteins onto unattached kinetochores (Santaguida et al., 2010). The observed increased expression of cyclin D in Rev-treated OA-HAC, instead, may be explained by the slippage of some cells from aberrant mitosis and re-entrance in the G1 phase; this interpretation is in accordance with the endoproliferation and polyploidy evidence also found in our study. Possibly a better general health condition of a "normal" chondrocyte (i.e. N-HAC, a nonfrank OA chondrocyte) enables the cell to react easily to exogenous stimuli and environmental variations: the undertaking of normal physiological responses, such as proliferation and metabolic activities, if with a sufficient momentum, would then result in protection from Rev effects. On the contrary, an OA-chondrocyte could represent an already sensitive target cell, prone to additional impairment. However not all the outcomes of Rev treatment are necessarily detrimental to the cell pro-chondrogenic properties. Indeed, we 
have provided data that Rev modulates OA-HAC gene expression; the transcript levels of SOX9, Aggrecan, TGF $\beta 1-3$ were up-regulated while those of IL 1- $\beta$ and IL-6 were decreased. This pattern could suggest that Rev stimulated the chondrogenic potential of OA-HAC, considering that SOX9, Aggrecan and TGFs are expressed by metabolic active chondrocytes, while IL 1- $\beta$ and IL-6 induce chondrocyte de-differentiation (Duan et al., 2015). However, the Rev-treated OA-HAC gene expression pattern appears rather aberrant, given i) the contemporary absence of enhancement of type II collagen expression in OA-HAC, which we, instead, observed in Rev-treated N-HAC; and ii) the increased expression of MMP13 and VEGF, which are upregulated in late hypertrophic chondrocytes involved in calcification of the cartilage ECM, or during the in vitro recapitulation of endochondral ossification induced by TGF-mediated signaling (Narcisi et al., 2012). However it should be also mentioned that IL-1 $\beta$ promotes prostaglandin E synthesis, which instead sustains cell differentiation and type II collagen expression (Tsuchida et al., 2014). Therefore a significant reduction in IL-1 $\beta$ transcript may exert opposite outcomes, and further evaluation of the cytokine downstream effectors will be needed to elucidate this finding. Concerning the observed modulation of SMAD3 and SMAD7 by Rev in OA-HAC, it should be noticed that the SMAD3 transcript level was barely altered and was not paralleled by an increased protein amount, nor by an enhanced content of the activated (i.e.phosphorylated) protein. In this respect, though, it is formally possible that timing could be a key issue to detect up-regulation(s) of a transient effect. On the other hand, the observed induction of the inhibitory SMAD7 mRNA may be a compensatory mechanism to counteract the enhanced transcription of genes, such as MMP13 and VEGF, normally active during the endochondral ossification pathway. We also observed that Rev induced a profound change of the OA-HAC morphology, switching cell shape from an elongated (fibroblast-like) appearance to a rounded/polygonal one. This 
modification was fully consistent with the observed tubulin and actin subcellular distribution patterns. We therefore suggest that all these morphological and gene expression changes induced by Rev in OA-HAC might be tightly interdependent. In fact chondrocytes sensitivity to microenvironmental changes and to their own tensegrity may contribute to alterations in gene expression (Ingber, 2006), as testified by their progressive de-differentiation once in a 2D environment (Goldring and Goldring, 2007). Ideally, in a proper microenvironment, cultured normal chondrocytes resume the original phenotype, although this ability depends upon the age and wealth status of the cells themselves (Giannoni et al., 2005). Given the morphological changes observed upon treatment with Rev, then, the di-substituted purine could be envisaged to maintain higher levels of residual plasticity potential in the cultured chondrocytes. Reversine-induced cell rounding and growth arrest could contribute to an exogenously imposed mimicry of the canonical quiescent state of the cell, which rules the low metabolic activity of articular chondrocytes in cartilage. This, in turn, may drive a higher transcriptional potential for a cartilage specific factor, such as SOX9, which can thus enhance the expression of additional extracellular matrix component, as Aggrecan, like it normally does in normal HAC cultures (Henry et al., 2012). Speculatively, the p300/CBP complex (p300/CREB-Binding Protein complex) could actively participate to these SOX9mediated mechanisms; indeed its acetyl-transferase activity (Ha et al., 2009), as well as its functions as a transcriptional co-activator (Goodman and Smolik, 2000), are of paramount relevance for chromatin condensation/decondensation dynamics during the $G 2 / M$ transition. Possibly, reversine-induced mitotic catastrophe could unleash p300/CBP from chromatin condensation. This, in turn, could provide a larger availability of the cotranscriptional complex for specific binding with other factors (Polesskaya et al., 2001) among which SOX9, as demonstrated for the SMAD3-driven p300-mediated transactivation 
of SOX9 during chondrogenesis (Furumatsu et al., 2005;Tsuda et al., 2003). In addition, also the TGF- $\beta$ overexpression, as we detected in Rev-treated samples, can positively regulate p300 (Ghosh et al., 2013). In Rev-treated cells, receptor clustering and interaction with membrane proteins could be hypothesized, as previously indicated (Rudini et al., 2008), to enhance the standard TGF-mediated signaling, indirectly contributing to the SMAD 3dependent non-canonical pathway (Bauge et al., 2011). In conclusion the effects elicited by Rev on survival and differentiation of OA-HAC, at the cell-cycle checkpoint and gene expression levels, may provide, at the most, a slightly enhanced pro-chondrogenic environment. In spite of this usefulness for experimental settings, the Reversine residual apoptotic/cytotoxic effects and the proposed results do not call for a true "rejuvenation property" of the molecule itself, nor for its current application in a clinical scenario.

\section{ACKNOWLEDGEMENTS AND STATEMENTS}

This work was supported in part by the University of Genova, Italy, grant n. PRA2013 CUP D34G13000170005.

All the authors declare no competing conflicts of interest.

\section{REFERENCES}

Alsalameh S, Amin R, Gemba T, Lotz M. 2004, Identification of mesenchymal progenitor cells in normal and osteoarthritic human articular cartilage, Arthritis Rheum, 50(5):1522-1532 
Amabile G, D'Alise AM, Iovino M, Jones P, Santaguida S, Musacchio A, Taylor S, Cortese R. 2009, The Aurora B kinase activity is required for the maintenance of the differentiated state of murine myoblasts, Cell Death Differ, 16(2):321-330

Bauge C, Cauvard O, Leclercq S, Galera P, Boumediene K. 2011, Modulation of transforming growth factor beta signalling pathway genes by transforming growth factor beta in human osteoarthritic chondrocytes: involvement of Sp1 in both early and late response cells to transforming growth factor beta, Arthritis Res Ther, 13(1):R23

Bijian K, Lougheed C, Su J, Xu B, Yu H, Wu JH, Riccio K, Alaoui-Jamali MA. 2013, Targeting focal adhesion turnover in invasive breast cancer cells by the purine derivative reversine, $\mathrm{Br}$ J Cancer, 109(11):2810-2818

Brandt KD, Dieppe P, Radin EL. 2008, Etiopathogenesis of osteoarthritis, Rheum Dis Clin North Am, 34(3):531-559

Chen S, Do JT, Zhang Q, Yao S, Yan F, Peters EC, Scholer HR, Schultz PG, Ding S. 2006, Selfrenewal of embryonic stem cells by a small molecule, Proc Natl Acad Sci U $S$ A, 103(46):17266-17271

Chen S, Takanashi S, Zhang Q, Xiong W, Zhu S, Peters EC, Ding S, Schultz PG. 2007, Reversine increases the plasticity of lineage-committed mammalian cells, Proc Natl Acad Sci U S A, 104(25):10482-10487

Chen S, Zhang Q, Wu X, Schultz PG, Ding S. 2004, Dedifferentiation of lineage-committed cells by a small molecule, J Am Chem Soc, 126(2):410-411

Dorotka R, Bindreiter U, Vavken P, Nehrer S. 2005, Behavior of human articular chondrocytes derived from nonarthritic and osteoarthritic cartilage in a collagen matrix, Tissue Eng, 11(5-6):877-886 
Duan L, Ma B, Liang Y, Chen J, Zhu W, Li M, Wang D. 2015, Cytokine networking of chondrocyte dedifferentiation in vitro and its implications for cell-based cartilage therapy, Am J Transl Res, 7(2):194-208

Furumatsu T, Tsuda M, Taniguchi N, Tajima Y, Asahara H. 2005, Smad3 induces chondrogenesis through the activation of SOX9 via CREB-binding protein/p300 recruitment, J Biol Chem, 280(9):8343-8350

Ghosh AK, Bhattacharyya S, Lafyatis R, Farina G, Yu J, Thimmapaya B, Wei J, Varga J. 2013, p300 is elevated in systemic sclerosis and its expression is positively regulated by TGF-beta: epigenetic feed-forward amplification of fibrosis, J Invest Dermatol, 133(5):1302-1310

Giannoni P, Pagano A, Maggi E, Arbico R, Randazzo N, Grandizio M, Cancedda R, Dozin B. 2005, Autologous chondrocyte implantation ( $\mathrm{ACl}$ ) for aged patients: development of the proper cell expansion conditions for possible therapeutic applications, Osteoarthritis Cartilage, 13(7):589-600

Goldring MB, Goldring SR. 2007, Osteoarthritis, J Cell Physiol, 213(3):626-634

Goodman RH, Smolik S. 2000, CBP/p300 in cell growth, transformation, and development, Genes Dev, 14(13):1553-1577

Ha GH, Kim HS, Lee CG, Park HY, Kim EJ, Shin HJ, Lee JC, Lee KW, Lee CW. 2009, Mitotic catastrophe is the predominant response to histone acetyltransferase depletion, Cell Death Differ, 16(3):483-497

Henry SP, Liang S, Akdemir KC, de Crombrugghe B. 2012, The postnatal role of Sox9 in cartilage, J Bone Miner Res, 27(12):2511-2525

Ingber DE. 2006, Cellular mechanotransduction: putting all the pieces together again, FASEB J, 20(7):811-827 
Jayasuriya CT, Zhou FH, Pei M, Wang Z, Lemme NJ, Haines P, Chen Q. 2014, Matrilin-3 chondrodysplasia mutations cause attenuated chondrogenesis, premature hypertrophy and aberrant response to TGF-beta in chondroprogenitor cells, Int J Mol Sci, 15(8):14555-14573

Johnstone B, Hering TM, Caplan AI, Goldberg VM, Yoo JU. 1998, In vitro chondrogenesis of bone marrow-derived mesenchymal progenitor cells, Exp Cell Res, 238(1):265-272

Jones EA, Crawford A, English A, Henshaw K, Mundy J, Corscadden D, Chapman T, Emery P, Hatton P, McGonagle D. 2008, Synovial fluid mesenchymal stem cells in health and early osteoarthritis: detection and functional evaluation at the single-cell level, Arthritis Rheum, 58(6):1731-1740

Karagiannis P, Yamanaka S. 2014, The fate of cell reprogramming, Nat Methods, 11(10):1006-1008

Kong X, Liu Y, Ye R, Zhu B, Zhu Y, Liu X, Hu C, Luo H, Zhang Y, Ding Y, Jin Y. 2013, GSK3beta is a checkpoint for TNF-alpha-mediated impaired osteogenic differentiation of mesenchymal stem cells in inflammatory microenvironments, Biochim Biophys Acta, 1830(11):5119-5129

Krawetz RJ, Wu YE, Martin L, Rattner JB, Matyas JR, Hart DA. 2012, Synovial fluid progenitors expressing CD90+ from normal but not osteoarthritic joints undergo chondrogenic differentiation without micro-mass culture, PLoS One, 7(8):e43616

Lee EK, Bae GU, You JS, Lee JC, Jeon YJ, Park JW, Park JH, Ahn SH, Kim YK, Choi WS, Kang JS, Han G, Han JW. 2009, Reversine increases the plasticity of lineage-committed cells toward neuroectodermal lineage, J Biol Chem, 284(5):2891-2901

Mardones R, Jofre CM, Minguell JJ. 2015, Cell Therapy and Tissue Engineering Approaches for Cartilage Repair and/or Regeneration, Int J Stem Cells, 8(1):48-53 
Murphy JM, Dixon K, Beck S, Fabian D, Feldman A, Barry F. 2002, Reduced chondrogenic and adipogenic activity of mesenchymal stem cells from patients with advanced osteoarthritis, Arthritis Rheum, 46(3):704-713

Musacchio A, Salmon ED. 2007, The spindle-assembly checkpoint in space and time, Nat Rev Mol Cell Biol, 8(5):379-393

Narcisi R, Quarto R, Ulivi V, Muraglia A, Molfetta L, Giannoni P. 2012, TGF beta-1 administration during ex vivo expansion of human articular chondrocytes in a serum-free medium redirects the cell phenotype toward hypertrophy, J Cell Physiol, 227(9):3282-3290

Otto FJ. 1994, High-resolution analysis of nuclear DNA employing the fluorochrome DAPI, Methods Cell Biol, 41211-217

Piccoli M, Palazzolo G, Conforti E, Lamorte G, Papini N, Creo P, Fania C, Scaringi R, Bergante S, Tringali C, Roncoroni L, Mazzoleni S, Doneda L, Galli R, Venerando B, Tettamanti G, Gelfi C, Anastasia L. 2012, The synthetic purine reversine selectively induces cell death of cancer cells, J Cell Biochem, 113(10):3207-3217

Pikir BS, Susilowati H, Hendrianto E, Abdulrantam F. 2012, Reversin increase the plasticity of bone marrow-derived mesenchymal stem cell for generation of cardiomyocyte in vitro, Acta Med Indones, 44(1):23-27

Polesskaya A, Naguibneva I, Fritsch L, Duquet A, Ait-Si-Ali S, Robin P, Vervisch A, Pritchard LL, Cole P, Harel-Bellan A. 2001, CBP/p300 and muscle differentiation: no HAT, no muscle, EMBO J, 20(23):6816-6825

Rudini N, Felici A, Giampietro C, Lampugnani M, Corada M, Swirsding K, Garre M, Liebner S, Letarte M, ten Dijke P, Dejana E. 2008, VE-cadherin is a critical endothelial regulator of TGFbeta signalling, EMBO J, 27(7):993-1004 
Santaguida S, Tighe A, D'Alise AM, Taylor SS, Musacchio A. 2010, Dissecting the role of MPS1 in chromosome biorientation and the spindle checkpoint through the small molecule inhibitor reversine, J Cell Biol, 190(1):73-87

Saraiya M, Nasser R, Zeng Y, Addya S, Ponnappan RK, Fortina P, Anderson DG, Albert TJ, Shapiro IM, Risbud MV. 2010, Reversine enhances generation of progenitor-like cells by dedifferentiation of annulus fibrosus cells, Tissue Eng Part A, 16(4):1443-1455

Tiku ML, Sabaawy HE. 2015, Cartilage regeneration for treatment of osteoarthritis: a paradigm for nonsurgical intervention, Ther Adv Musculoskelet Dis, 7(3):76-87

Tsuchida Al, Beekhuizen M, t Hart MC, Radstake TR, Dhert WJ, Saris DB, van Osch GJ, Creemers LB. 2014, Cytokine profiles in the joint depend on pathology, but are different between synovial fluid, cartilage tissue and cultured chondrocytes, Arthritis Res Ther, $16(5): 441$

Tsuda M, Takahashi S, Takahashi Y, Asahara H. 2003, Transcriptional co-activators CREBbinding protein and p300 regulate chondrocyte-specific gene expression via association with Sox9, J Biol Chem, 278(29):27224-27229

Wilmut I, Schnieke AE, McWhir J, Kind AJ, Campbell KH. 1997, Viable offspring derived from fetal and adult mammalian cells, Nature, 385(6619):810-813

Ying QL, Nichols J, Evans EP, Smith AG. 2002, Changing potency by spontaneous fusion, Nature, 416(6880):545-548 
Figure 1

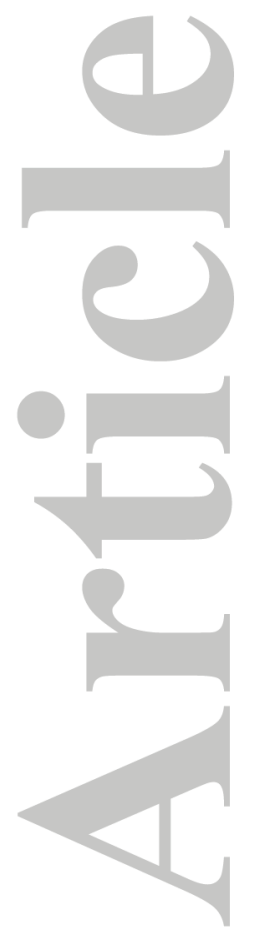

A
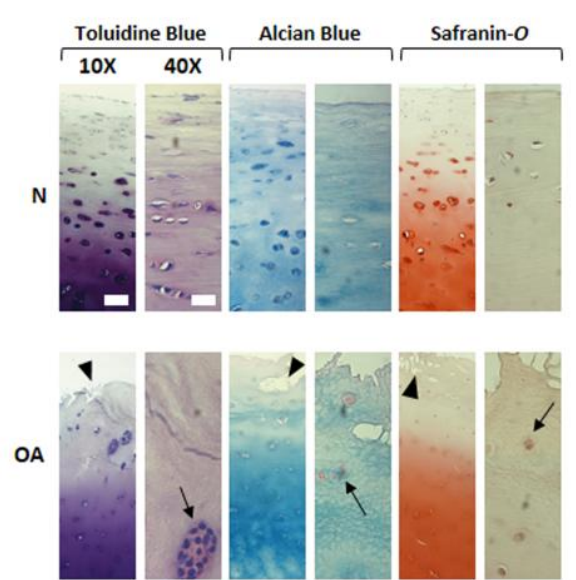

C

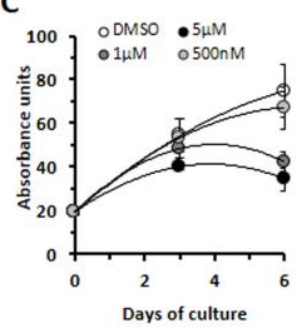

B
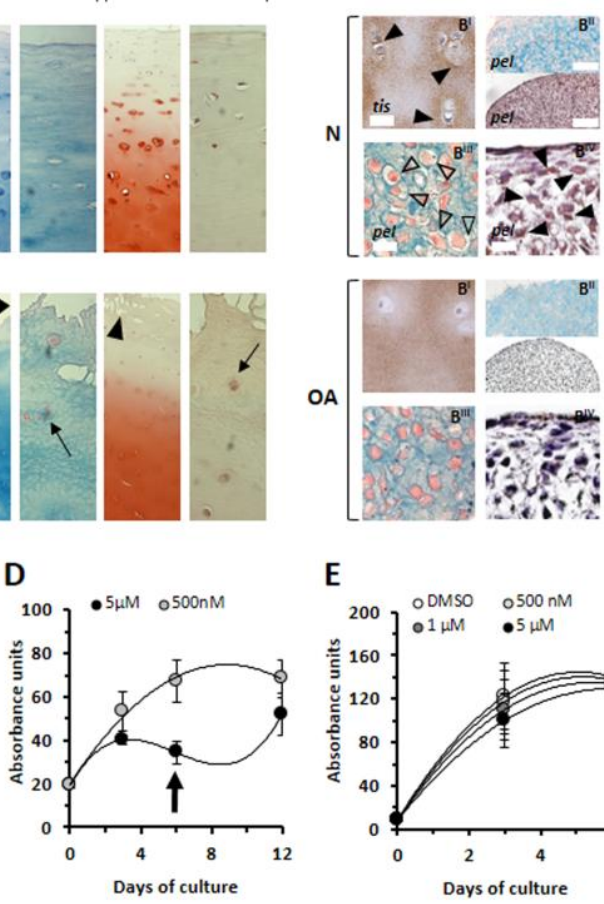

E

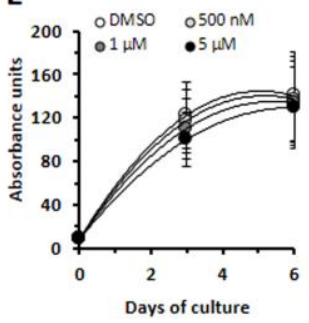

\section{Figure 1.}

A: Toluidine blue, Alcian blue and Safranin-O staining of sections from control (N) or osteoarthritic cartilage (OA) from human donors; depicted sections are representative of the specimens derived from $\mathrm{N}$ and $\mathrm{OA}$ areas of the tissue of each donor. Arrowheads indicate evidence of fibrillation; arrows: cell proliferation. White bars: $100 \mu \mathrm{m}$ and $25 \mu \mathrm{m}$ (for 10X and 40X enlargements, respectively). B: Representative anti- type II collagen and Alcian Blue staining of original tissue sections (tis) or radial sections of micromass cultures (pel) of $\mathrm{N}$ or $\mathrm{OA}$ HAC derived from the same donor. $\mathrm{B}^{\prime}$ : representative images of immunopositivity to anti-type II collagen antibody of original tissue sections (tis) derived from $\mathrm{N}$ or $\mathrm{OA}$ areas of the same bioptic specimen; white bars: $10 \mu \mathrm{m}$. $\mathrm{B}^{\mathrm{II}}$ : representative low magnification images of sections of micromass cultures (pel) derived from $\mathrm{N}$ or OA cells of the same specimen, stained with alcian blue (upper) or anti-type II collagen antibody 
(lower), respectively; white bars: $100 \mu \mathrm{m}$. $\mathrm{B}^{\mathrm{III}}$ : representative sections of micromass cultures (pel) derived from $\mathrm{N}$ or $\mathrm{OA}$ cells of the same specimen stained with Alcian blue; empty arrowheads indicate lacunae in the process of maturation; white bars: $10 \mu \mathrm{m} . B^{\mathrm{IV}}$ : representative sections of micromass cultures (pel) derived from $\mathrm{N}$ or OA cells of the same specimen challenged with anti-type II collagen antibody; black arrowheads indicate positive cells. C: Proliferation kinetics of control (DMSO alone) and Reversine-treated OA HAC; treated cells were exposed to $500 \mathrm{nM}, 1.0 \mu \mathrm{M}$ and 5.0 $\mu \mathrm{M}$ Reversine, in DMSO, respectively. Each data point represents the average of the determinations performed on three different primary cultures, in two separate sets of experiments; each time point, for each primary culture and condition, was assessed in quadruplicate. Error bars depict standard deviation values. D: Proliferation kinetics of $5.0 \mu \mathrm{M}$ Rev-treated OA HAC after shifting to a lower concentration of the chemical (500 nM; arrow). The proliferation curve of $500 \mathrm{nM}$ Revtreated cells is also depicted for comparison. Data points as in C. E: Proliferation kinetics of control (DMSO alone) and Reversine-treated chondrocytes derived from normal cartilage; legend and data points as in C.

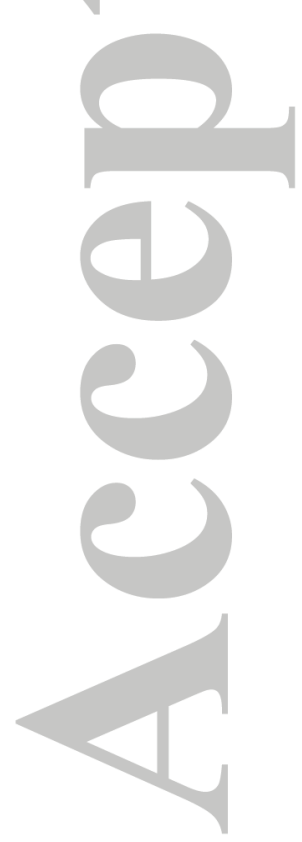


Figure 2

A
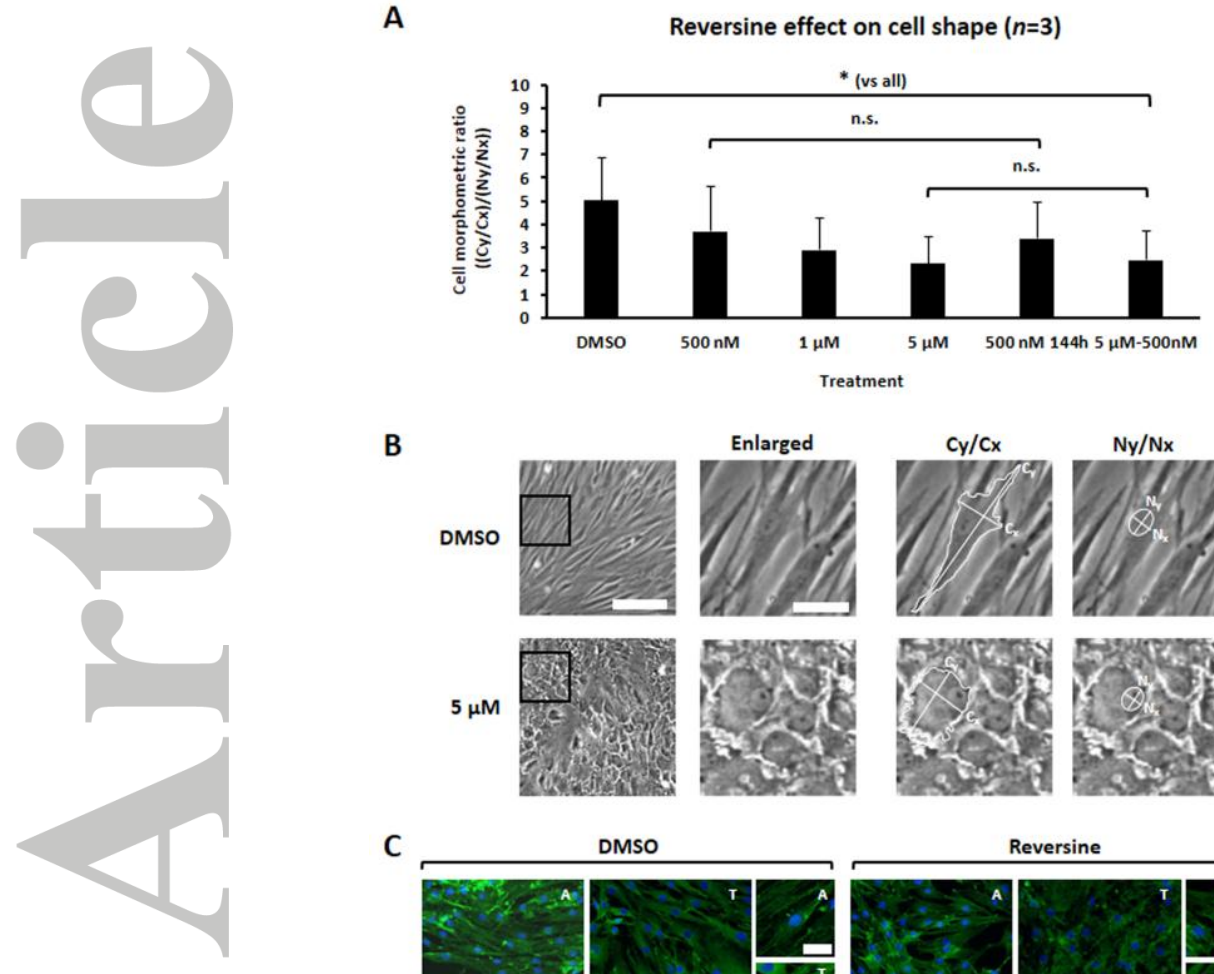

B
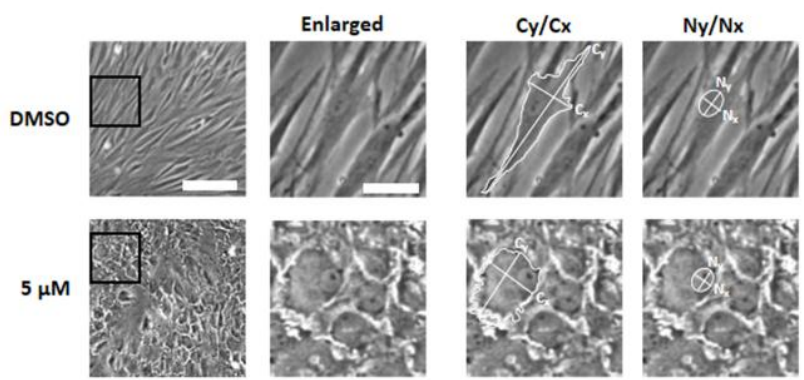

C
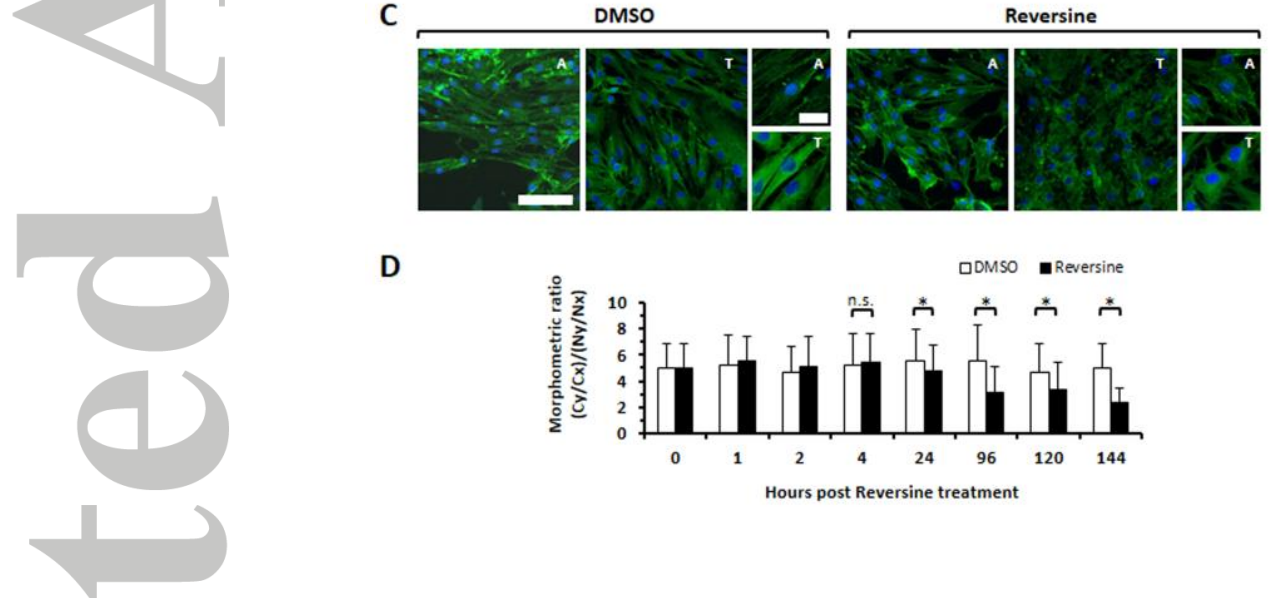

D

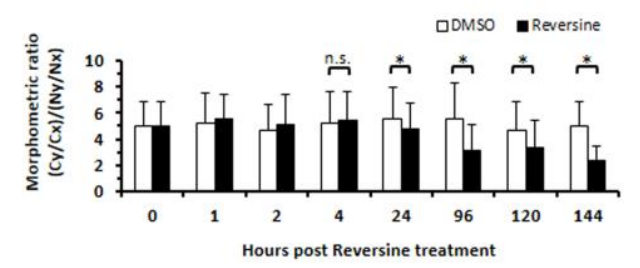

Figure 2.

A: Evaluation of morphological changes induced in cultured OA HAC by exposure to Reversine. Cell morphological parameters were assessed in a minimum of 100 cells/treatment for each primary culture $(n=3)$. Histograms depict the average ratio $(\mathrm{Cy} / \mathrm{Cx}) /(\mathrm{Ny} / \mathrm{Nx})$, as defined under the Material and Methods section; error bars depict standard deviation values; treatments include control (DMSO) and Reversine exposure (500 $\mathrm{nM}, 1.0 \mu \mathrm{M}$ and $5.00 \mu \mathrm{M})$ for 6 days. Cell aliquots of each primary culture were also exposed to Rev 500 nM for 6 additional days (Rev 500 nM 144h) or exposed to Rev $5.0 \mu M$ for 6 days and then shifted to Rev $500 \mathrm{nM}(5.0 \mu \mathrm{M}-500 \mathrm{nM})$ for 6 additional days. Statistical 
significance $\left({ }^{*}\right)$ was proved for each treatment with respect to DMSO (vs all); n.s.: not significant. B: representative images of control (DMSO) or Reversine-treated cells (5.0 $\mu \mathrm{M})$; boxed areas in images of the left column are enlarged and show the assessed morphological parameters; white bars: $50 \mu \mathrm{m}$ (panels in left column), $10 \mu \mathrm{m}$ (in Enlarged, $\mathrm{Cy} / \mathrm{Cx}$ and Ny/Nx colums). $C$ : $\beta$-actin (A) or $\beta$-tubulin (T) immunofluorescence staining of control (DMSO) or Reversine-treated cells $(5.0 \mu \mathrm{M})$; white bars: $25 \mu \mathrm{m}$ or $10 \mu \mathrm{m}$, for large or small panels, respectively. D: Kinetics of morphological changes in cultured control (DMSO; empty bars) or Reversine-treated (Reversine, $5.0 \mu \mathrm{M}$; solid bars); morphological parameters were assessed in a minimum of 100 cells/treatment for each primary culture $(n=3)$; error bars depict standard deviation values.

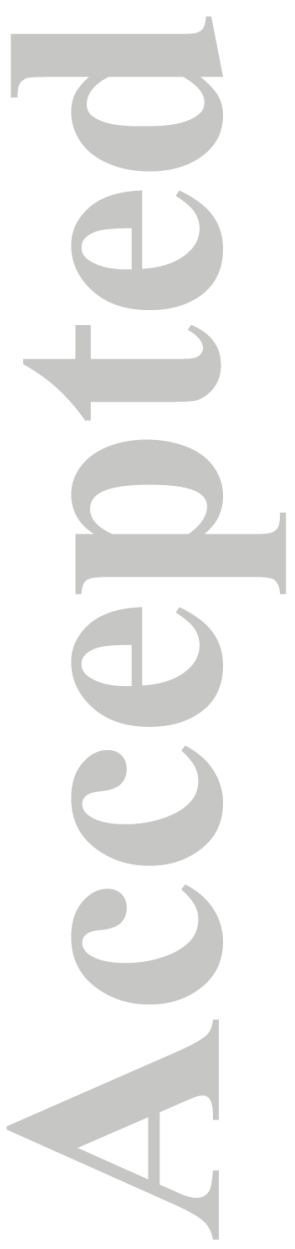




\section{Figure 3}

A

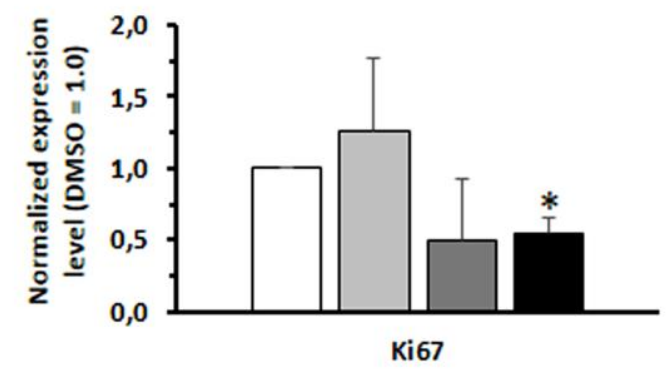

B

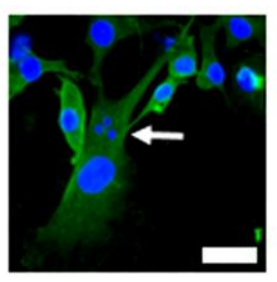

C
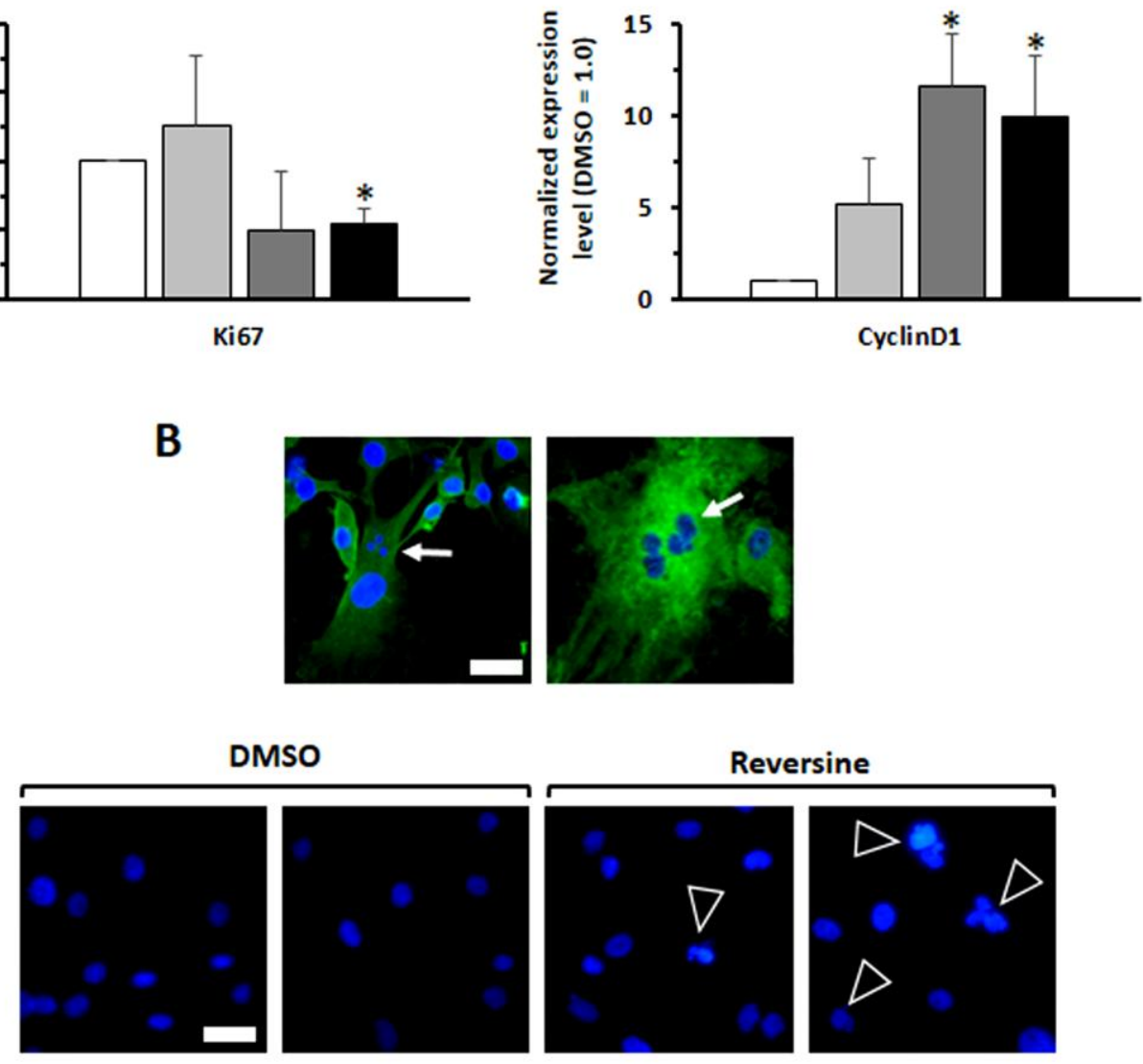

D

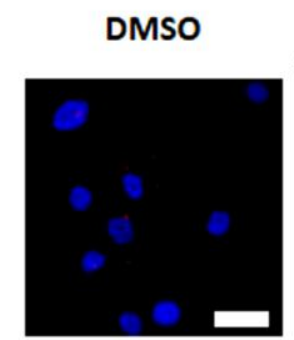

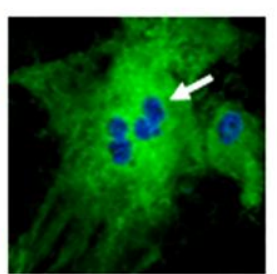

Reversine

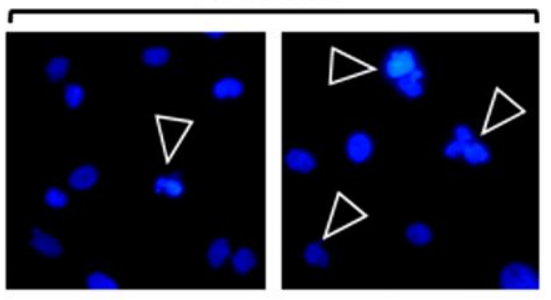

Reversine

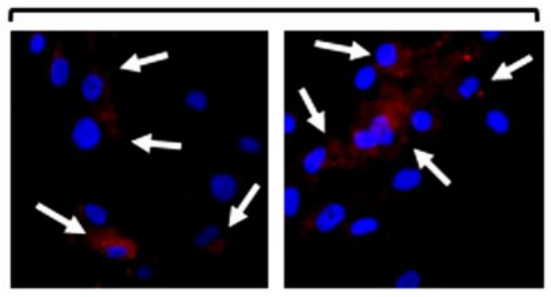

Figure 3.

A: Relative transcript levels of Ki67 (left) and Cyclin D1 (right) in control (DMSO alone, white bars) and Reversine-treated OA HAC samples (500 nM, light grey bars; $1.0 \mu \mathrm{M}$, dark grey bars; and $5.0 \mu \mathrm{M}$, black bars, respectively). Results depict the average expression of 3 different primary OA HAC cultures and are normalized to controls. Error bars represent 
standard deviations. B: Polynucleated cells evidenced by nuclear DAPI staining in Revtreated $(5.0 \mu \mathrm{M}) \mathrm{HAC}$, challenged with anti- $\beta$ actin and FITC-conjugated secondary antibody. Arrows point to multinuclear cells. C: DAPI nuclear staining in control (DMSO) or in Reversine-treated (5.0 $\mu \mathrm{M})$ OA HAC; arrowheads point to multiple and apoptotic nuclei. D: Caspase- 3 positive OA HAC after Reversine treatment (5.0 $\mu \mathrm{M}$; arrows). White bars: $10 \mu \mathrm{m}$.

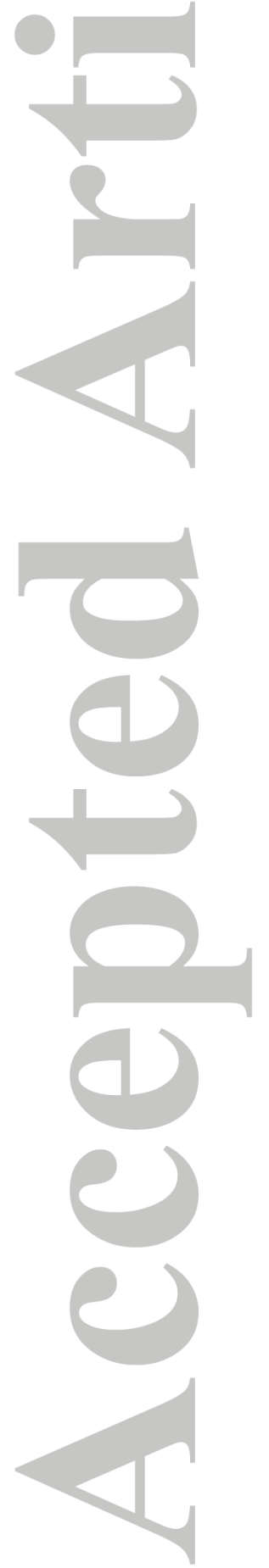


Figure 4

A

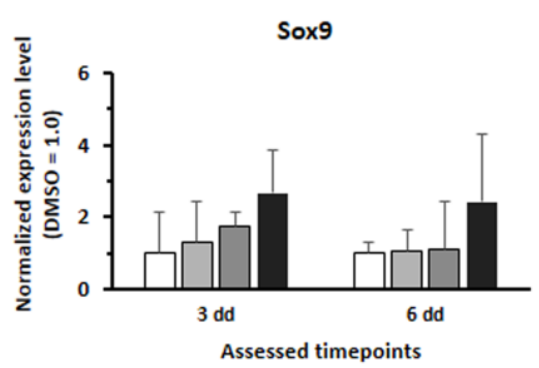

D

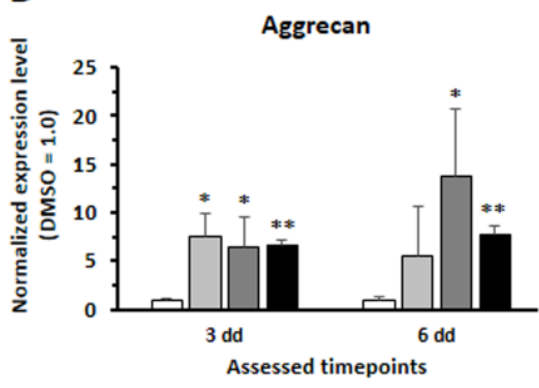

$\mathbf{F}$

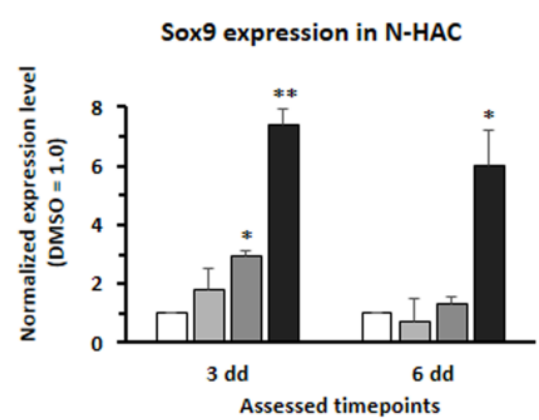

B

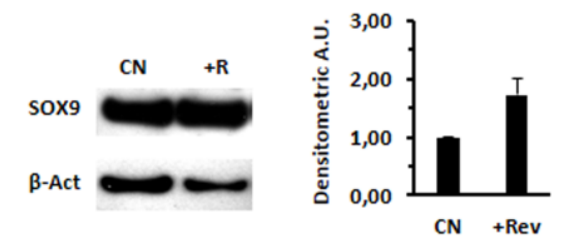

$\mathbf{E}$

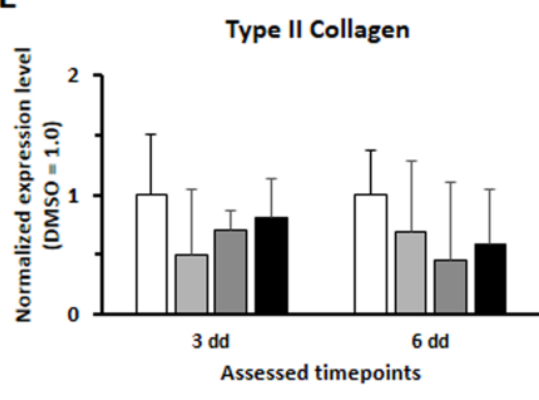

G

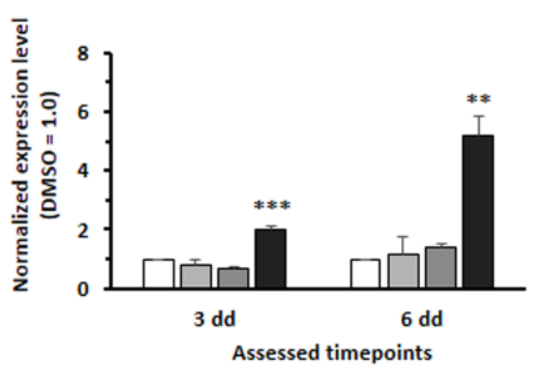

Figure 4.

A: SOX9 relative transcript levels in DMSO or Rev-treated OA HAC after 3 and 6 days of exposure to Reversine as assessed by real time RT-PCR. Histograms refer to controls (DMSO alone, white bars) and Reversine-treated OA HAC samples (500 nM, light grey bars; $1.0 \mu \mathrm{M}$, dark grey bars; and $5.0 \mu \mathrm{M}$, black bars, respectively). Histograms depict the average expression of 3 different primary OA HAC cultures and are normalized to controls. Error bars depict standard deviations. B: Representative immunoblot against SOX9 and $\beta$-Actin ( $\beta$-Act) in control (CN) and Rev-treated (+R; $5.0 \mu \mathrm{M}$ at 6 days) OA HAC lysates. C: Densitometric 
analysis of the ratio of SOX9/ $\beta$-Actin protein levels. Histograms represent the average of the determinations performed on lysates of two different OA HAC primaries; results are expressed as arbitrary densitometric units (A.U.) and normalized to controls; error bars depict standard deviations. D-E: Gene expression analysis of Aggrecan (D) or Type II Collagen (E) in control or Rev-treated OA HAC after 3 and 6 days of exposure. F-G: Gene expression analysis of SOX9 (F) or Type II Collagen (G) in control or Rev-treated N HAC after 3 and 6 days of exposure. Results are the average of three different primary culture tested; error bars depict standard deviations.
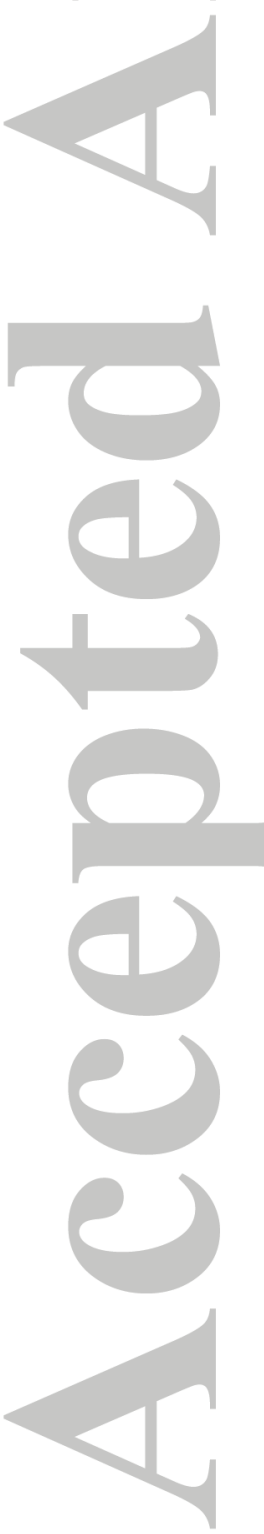


\section{Figure 5}
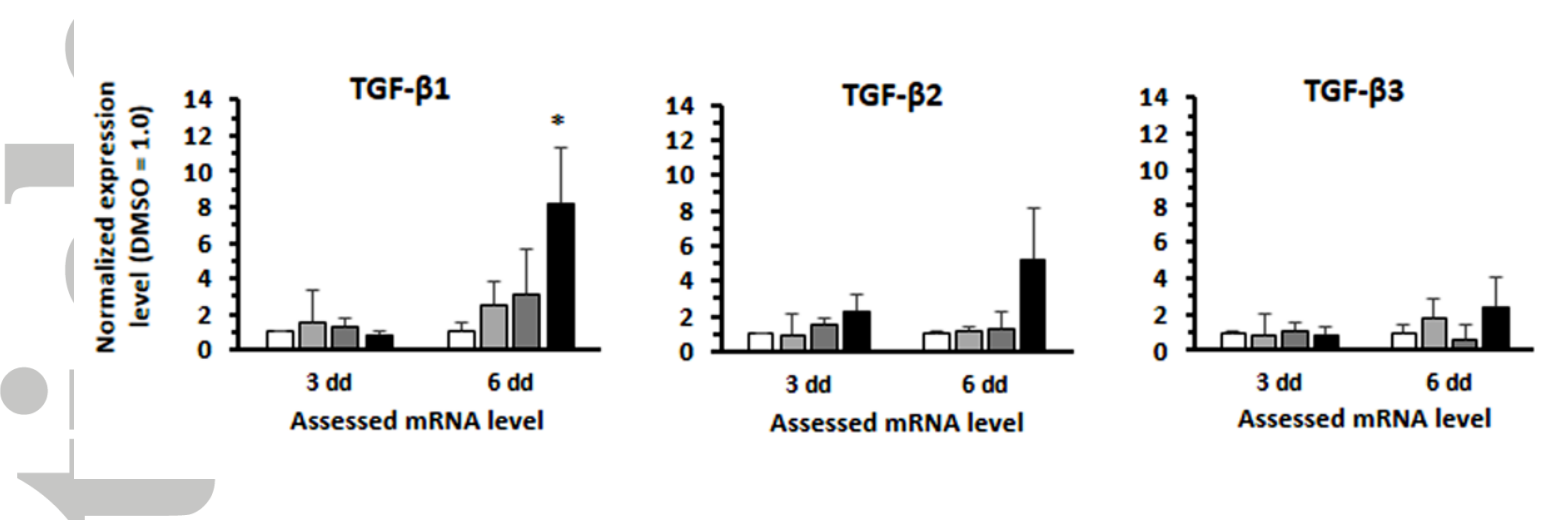

\section{Figure 5.}

Real time RT-PCR gene expression analysis of the relative transcript levels for TGF $\beta-1,-2$ and -3 in control and Rev-treated OA HAC after 3 and 6 days of exposure to Reversine. Histograms refer to controls (DMSO alone, white bars) and Reversine-treated OA HAC samples (500 nM, light grey bars; $1.0 \mu \mathrm{M}$, dark grey bars; and $5.0 \mu \mathrm{M}$, black bars, respectively) and display the average values of three different primary cultures tested; data are normalized to controls; error bars depict standard deviations. 


\section{Figure 6}

A

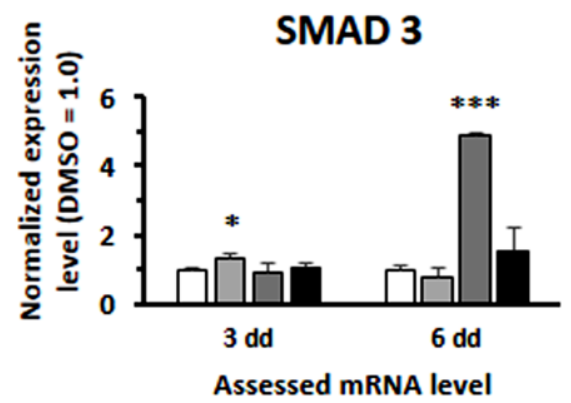

D

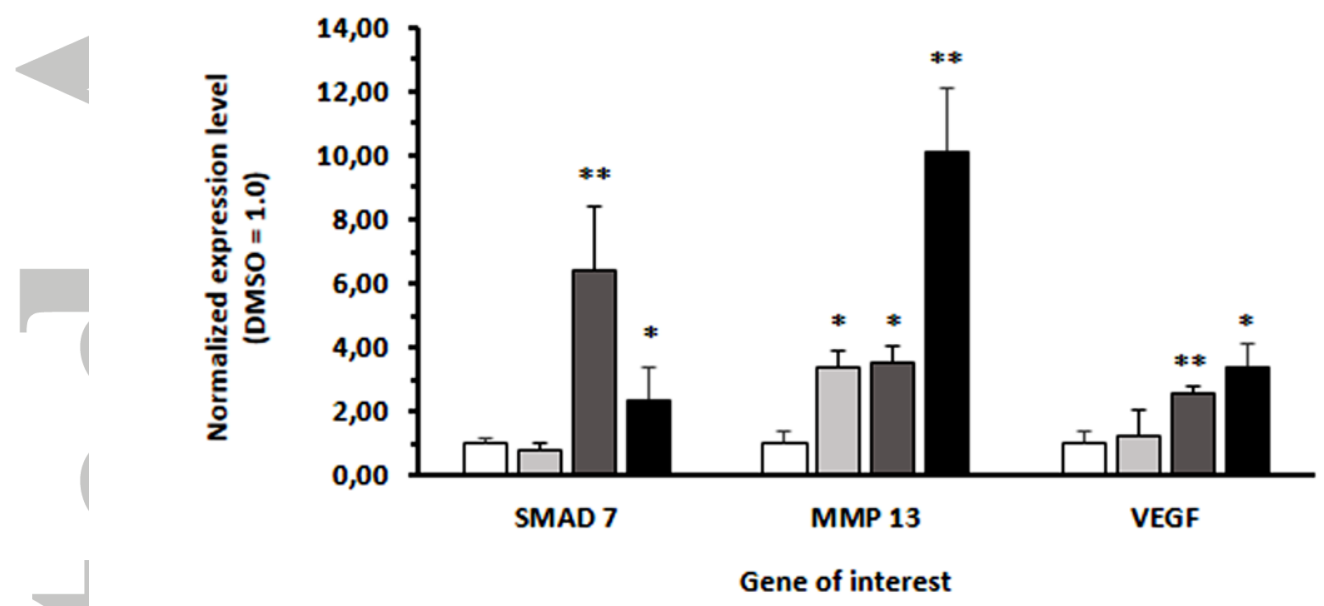

$\mathbf{E}$ Expression pattern after 6 dd of Reversine treatment

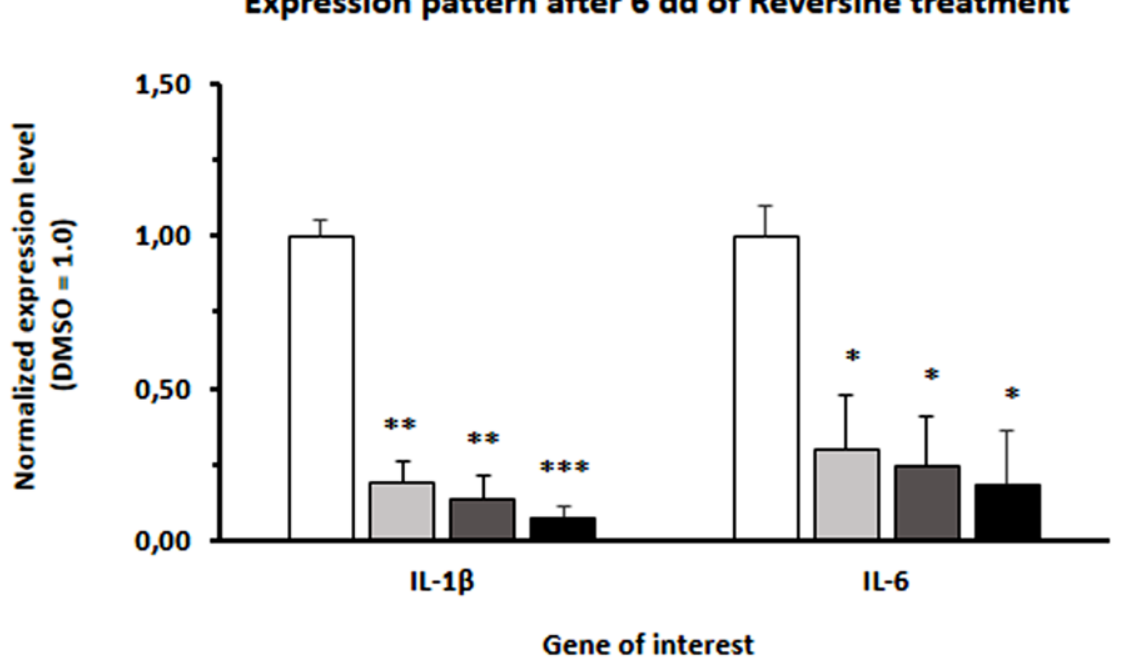

Figure 6.

Expression pattern after $\mathbf{6}$ dd of Reversine treatment
B

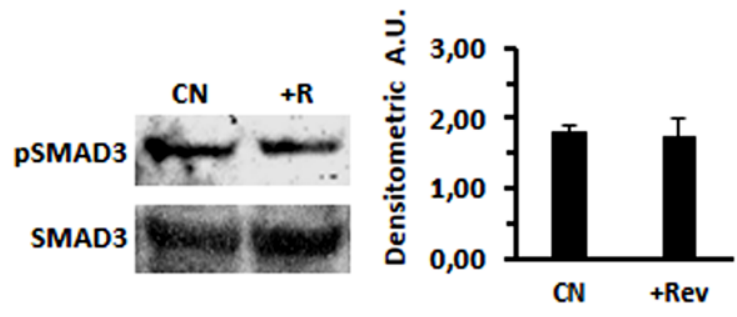

This article is protected by copyright. All rights reserved. 
A: SMAD3 relative transcript levels in DMSO or Rev-treated OA HAC after 3 and 6 days of exposure to Reversine as assessed by real time RT-PCR. Results depict the average expression of 3 different primary OA HAC cultures and are normalized to controls. Histograms refer to controls (DMSO alone, white bars) and Reversine-treated OA HAC samples (500 nM, light grey bars; $1.0 \mu \mathrm{M}$, dark grey bars; and $5.0 \mu \mathrm{M}$, black bars, respectively). Error bars depict standard deviations. B: Representative immunoblot against phosphorylated SMAD3 (pSMAD3) and total SMAD3 in control (CN) and Rev-treated (+R; 5.0 $\mu \mathrm{M}$ at 6 days) OA HAC lysates. C: Densitometric analysis of the ratio of pSMAD3/ $\beta-A c t i n$ protein levels. Histograms represent the average of the determinations performed on lysates of two different OA HAC primaries; results are expressed as arbitrary densitometric units (A.U.) and normalized to controls; error bars depict standard deviations. D: Gene expression analysis of SMAD7, MMP-13 and VEGF in DMSO- or Rev-treated OA HAC after 6 days of exposure to different concentrations of Reversine. E: Gene expression analysis of IL$1 \beta$ or IL- 6 in control or Rev-treated OA HAC after 6 days of exposure. Histograms refer to controls (DMSO alone, white bars) and Reversine-treated OA HAC samples (500 nM, light grey bars; $1.0 \mu \mathrm{M}$, dark grey bars; and $5.0 \mu \mathrm{M}$, black bars, respectively). Results are the average of three different primary culture tested; error bars depict standard deviations.

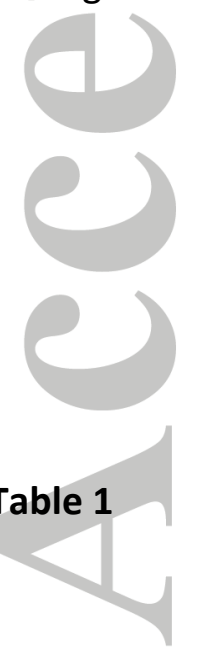

Custom-designed primer sequences

This article is protected by copyright. All rights reserved. 


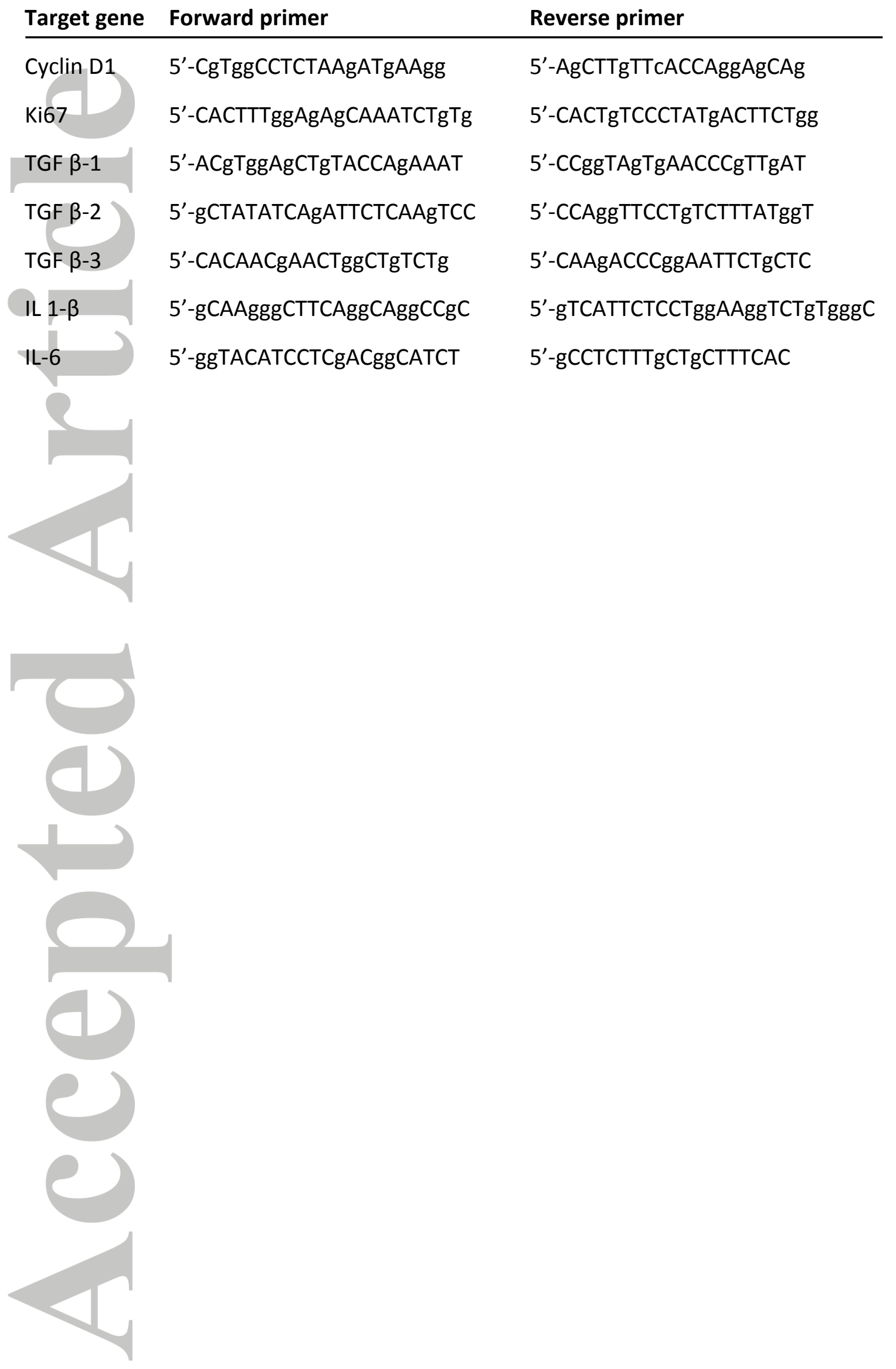

